\title{
Delivery and evaluation of a pilot obesity prevention project for urban Appalachian children
}

\author{
Laura Nabors $^{1 \#}$, Michelle Burbage ${ }^{1}$, Jordan Pangallo ${ }^{1}$, Amy Bernard ${ }^{1}$, Amanda Strong ${ }^{1}$, \\ Sarah Gardocki ${ }^{1}$, Phyllis Shelton ${ }^{2}$, Donna Jones ${ }^{2}$ \\ ${ }^{1}$ University of Cincinnati, Cincinnati, USA \\ ${ }^{2}$ Urban Appalachian Council, Cincinnati, USA \\ Email: "
}

Received 11 September 2013; revised 8 October 2013; accepted 15 October 2013

Copyright (C) 2013 Laura Nabors et al. This is an open access article distributed under the Creative Commons Attribution License, which permits unrestricted use, distribution, and reproduction in any medium, provided the original work is properly cited.

\begin{abstract}
Prevention of childhood obesity is a national concern and there is a need for interventions that can be implemented in community programs and are brief in nature. This pilot project was developed to evaluate the impact of the Children's Healthy Eating and Exercise Program, which was adapted from the Traffic Light Diet. Participants were urban Appalachian children and adolescents who were enrolled in one of two community-based summer programs. Quantitative and qualitative methods were used to examine children's impressions of the program and to assess what they learned during implementation of the program. Results indicated that younger children reported consuming fewer French fries or chips and older children reported eating more vegetables at the end of the program. Knowledge of two categories of Traffic Light foods appeared good; however, participants showed lower knowledge about one of the food categories. Future studies should involve parents as well as incorporate a more rigorous evaluation design with a comparison group to examine the impact of this new program.
\end{abstract}

Keywords: Obesity Prevention Program for Children

\section{INTRODUCTION}

With childhood obesity at epidemic proportions in our nation, there is a growing need to find effective ways to combat the problem and decrease children's risk for health hazards that result from unhealthy lifestyles [1]. Since, overweight children face significant risk of re-

\footnotetext{
*Appreciation is extended to the Urban Appalachian Council for their support of this project as well as to the Greater Cincinnati Foundation which provided funding through a Summertime Kids grant.

\#Corresponding author.
}

maining obese and health risks in adulthood, early intervention and prevention efforts are needed to address this serious health problem [2]. Riggs et al. suggested that prevention programs aimed at improving knowledge about healthy eating and exercise, to encourage the development of healthy lifestyles and prevent obesity are needed [3]. Translating effective intervention into community-based prevention programs is an important goal for researchers [4].

Children and adolescents are bombarded by information about "junk food" [5]. Moreover, snack foods that are relatively high in calories and have reduced nutritional value are often more readily available than fruits and vegetables [6]. Children in urban, low-income areas are at risk for becoming overweight and may have poor access to healthy food choices [7]. Goals of the current pilot project were to describe the initial implementation and evaluation of a healthy eating and exercise program for children residing in low-income families in an urban Appalachian area. There are a few studies assessing prevention programming for Appalachian youth residing in rural areas [8]. However, information is lacking about obesity prevention programs for Appalachian youth in urban settings. Additionally, programs typically are delivered in school or clinic settings, and more research is needed on prevention programs delivered in other community settings, such as church programs or community centers [4].

The current program was based on the Traffic or Stop Light Diet developed by Leonard Epstein [9]. Schetzina et al. implemented the Winning with Wellness Pilot Project at a school in Tennessee, and the Traffic Light Diet influenced their program as well [8]. The Winning with Wellness Project promoted healthy eating and increased activity at an elementary school in a rural Appalachian area. The three categories of foods in the Winning with Wellness Project were adapted from the Traffic Light 
Diet. The Traffic Light Diet emphasizes "red" or whoa foods (e.g., foods and beverages that are high in calories), "yellow" or slow foods (e.g., pasta; foods in the midrange in terms of calories) and "green" or good foods (e.g., fruits and vegetables; foods are often high in nutritional value). Similarly, the Winning with Wellness Project was developed by a registered dietician and emphasized "go" (fruits and vegetables), "slow" (pasta), and "whoa" (cake) food choices. Initial findings for the Winning with Wellness Project indicated positive change in school practices and policy as well as improved nutrition in food choices at school and increased physical activity for children during the school day. Difficulty implementing the program due to academic demands during the school day was mentioned as a barrier to program sustainability [8].

In addition to emphasizing eating more "green" and fewer "red" foods, the Traffic Light Diet also emphasizes the importance of exercise to maintain a healthy weight $[9,10]$. Exercise is a primary intervention to treat childhood obesity [11] and is also an intervention recommended to prevent obesity in children [12]. Children need to learn the importance of reducing "screen time" (i.e., time in front of the television and computer) and improve their involvement in activities, even those of lower intensity levels, such as walking, yoga and slowpaced dancing. The schools are targeted settings for improving children's activity levels; however, changing policies to implement more activities during the school day can be difficult due to academic demands. Thus, community programs are another avenue for teaching children about increasing their exercise levels and promoting increased physical activity, and thus improving activity.

The design of the Children's Healthy Eating and Exercise Program also was influenced by key concepts from motivational interviewing, a promising teaching and counseling technique for providing prevention messages and information about healthy living to children [13]. For our program, children learned about the importance of setting healthy eating and exercise goals to work in each week. They learned about "psyching up to stay healthy!" The groups also favored participation in projects and activities to keep the children active and engaged. Consequently, children developed projects, such as commercials to promote healthy eating for other children, games, cheers to promote healthy eating, and art activities to record what they learned. Many of the activities capitalized on the oral tradition and story-telling orientation prevalent in the Appalachian community [14]. The participatory approach used in developing work products to showcase children's learning was beneficial and allowed children to capitalize on creative ideas to present what they were learning. Qualitative methods were used to evaluate information provided to children about their creative projects and pre- and postintervention surveys were evaluated by using quantitative methods.

\section{METHOD}

\subsection{Participants}

Participants were 36 children in two different groups. One group was conducted at a local church. There were 17 youth ( 4 boys and 13 girls; $M=8$ years, $S D=4$ years, range $=4-16$ years) in this group, entitled the "younger" group. Seven children in the younger group were Caucasian, 7 were African American, 2 were Hispanic, and 1 was biracial. There were 19 adolescents in the "older" age group ( 9 males and 10 females; $M=16.21$ years, $S D$ $=1.18$ years, range $=14-18$ years $)$. The group for older youth was conducted in a meeting room at the local Urban Appalachian Council (UAC) building. The adolescents in this group were participating in a summer work program sponsored by the UAC. Eight adolescents in this group were Caucasian, 9 were African American and 2 were biracial. This study was approved by a universitybased institutional review board; parent permission and child assent were required for participation.

\section{Description of Activities in the Children's Healthy Eating and Exercise Program}

Group leaders reviewed foods that could be cooked or made for healthy meals at several sessions, focusing on how to combine predominantly green and yellow foods, with red foods as something a child would eat once in a while. As a rule of thumb, children were told to try to, "Eat four green foods for every red food". At subsequent sessions, students in both groups learned about packing healthy lunches. Children in the younger group drew pictures and discussed healthy lunches, while the children in the older group met in small groups to talk about eating a healthy lunch at school and packing a healthy lunch. Ideas for healthy snacks consisting of fruit and vegetables were reviewed in a discussion in both the younger and older children's groups. Children in the younger group completed the "What's in my Refrigerator Exercise" where they drew the foods in their refrigerator and then discussed what types of healthy foods were in their refrigerators and processed ideas for eating more healthy foods. The older youth made commercials and songs as exercises with instructions to teach younger children about how they could eat more red, yellow, and green light foods.

In the small group meetings children discussed ways to reward and motivate themselves to eat more fruits and vegetables and exercise every day. Handouts for parents included a review of red, yellow, and green foods and recipes to develop healthy meals based on use of primar- 
ily yellow and green foods. Handouts for parents with healthy recipes were provided for participants to take home and give to parents.

Several other activities, emphasizing the importance of increasing daily activity levels, were completed weekly in both the younger and older groups. Group leaders reviewed exercises one could do while sitting in a chair (e.g., leg lifts, arm waves). Information from the "Let's Move" website (www.letsmove.gov) was discussed with children in both groups. At each session the children exercised or discussed the importance of 20 - 30 minutes of daily exercise. Several activities were reviewed as being important to build into a weekly exercise routine including: dance, morning stretches and jumping jacks, playing a favorite game outside, becoming involved in a favorite sport, and walking after a meal and around the neighborhood with friends. Moreover, during groups facilitators reviewed easy exercises children could do during television commercials (such as scissor kicks, dancing, and jumping jacks) and ideas for reducing time spent being sedentary or in front of a television or computer screen. Children discussed healthy eating and exercise goals in small groups with facilitators each meeting. They identified goals for themselves and discussed how they progressed each week toward their goals.

The older children participated in 5 groups, whereas the younger children participated in 6 groups. Groups for the adolescents or the older group lasted for about 45 mins. The groups for younger children lasted for at least 90 mins. And children had more time to exercise and eat a healthy meal. For the younger group, dance was reviewed as an important exercise. Children danced to music from DVDs playing children's songs at most group meetings. The younger children ate a meal at the end of each group and the team for this project cooked healthy meals using primarily yellow and green stoplight diet foods, such as chicken quesadillas, pizza wheat bagels, salads, and plenty of fruit and vegetable plates. Meals were a chance to reinforce what foods comprised a healthy meal and ideas from My Plate.

\subsection{Procedures}

Before the intervention began, in the first session, children completed questions to examine what they ate yesterday. Questions addressed how many times they ate the following: 1) chips and fries (chips were defined as potato, corn, and tortilla chips, Cheetos, and other snack chips), 2) vegetables, 3) fruits, and 4) sweet rolls, doughnuts, cookies, brownies, pies or cake. Children selected one of four responses including 1) never, 2) 1 time, 3) 2 times, or 4) 3 or more times. Children also answered this question about exercise, "On how many days in the past 7 days did you engage in activity that made your heart beat fast and made you breathe hard for at least 20 minutes?" Children were provided with pictures of activities and they were listed (e.g., tennis, basketball, swimming, dancing, running). Children selected an answer from eight items from "0 days", "1 day", "2 days", ...up to "7 days". Children participated in the weekly groups described in the previous section of this paper. Group leaders recorded their impressions of children's participation in and comments about different group activities. At the end of the final session, children again completed the nutrition and exercise questions and they also completed a question where they wrote or discussed what they learned during the intervention about healthy eating.

\section{RESULTS}

Five paired t-tests were performed to analyze pre-post intervention change in consumption of French Fries and chips (potato chips, Cheetos, or any other snack chip), vegetables, fruits, sweet rolls, donuts, cookies, brownies, pies, and cake, and engaging in physical activity for children in the older and younger groups. A Bonferroni correction was used to adjust the alpha levels for the five t-tests.

Fourteen of the participants in the older group completed the pre- and post-test questionnaire. The means and standard deviations for their answers to the five questions are presented in Table $\mathbf{1}$.

There was a significant change in eating vegetables, $t(1,13)=-6.431, p=0.001$. The older youth consumed more vegetables at post-test compared to their responses at the pretest assessment. There were no significant differences for the other items at the two time points. Fourteen of the children in the older group completed a question assessing their perceptions of whether participating in the Healthy Eating classes improved their knowledge about healthy eating. Ninety-two percent $(n=13)$ reported that participating in the classes improved their knowledge. Specifically, 2 reported that their knowledge

Table 1. Results of paired t-tests for healthy eating questions for children in the older group.

\begin{tabular}{ccccc}
\hline Item & \multicolumn{2}{c}{ Pretest } & \multicolumn{2}{c}{ Post-test } \\
\hline $\begin{array}{c}\text { French fries } \\
\text { and chips }\end{array}$ & 0.786 & 0.802 & 0.714 & 0.994 \\
$\begin{array}{c}\text { Vegetables } \\
\text { Fruits }\end{array}$ & 0.571 & 0.756 & 3.07 & 1.071 \\
$\begin{array}{c}\text { Sweet rolls, donuts, } \\
\text { cookies }\end{array}$ & 0.9286 & 0.917 & 0.9286 & 0.829 \\
Exercise & 2.286 & 2.054 & 2.714 & 2.431 \\
\hline
\end{tabular}

Note. ${ }^{*}$ Significant different between pre- and post-test means. 
Table 2. Results of paired t-tests for healthy eating questions for children in the younger group.

\begin{tabular}{ccccc}
\hline Item & \multicolumn{2}{c}{ Pretest } & \multicolumn{2}{c}{ Post-test } \\
\hline M & SD & $M$ & $S D$ \\
$\begin{array}{c}\text { French fries } \\
\text { and chips }\end{array}$ & 1.143 & 0.690 & 0.429 & 0.535 \\
Vegetables & 1.00 & 0.577 & 1.714 & 0.756 \\
$\quad$ Fruits & 0.7143 & 0.756 & 1.286 & 0.951 \\
$\begin{array}{c}\text { Sweet rolls, } \\
\text { donuts, cookies }\end{array}$ & 1.857 & 0.900 & 0.8571 & 0.690 \\
Exercise & 3.714 & 2.138 & 3.286 & 3.498 \\
\hline
\end{tabular}

Note. "Significant different between pre- and post-test means.

improved, 5 reported that their knowledge improved "a lot", and 6 reported "amazing improvement". One youth reported that participating in the healthy eating groups did not improve knowledge.

Seven children in the younger group completed preand post-test data on the questionnaire. The means and standard deviations for each question/item are presented in Table 2.

There was a significant change in eating French Fries and chips, $\mathrm{t}(1,6)=3.873, \mathrm{p}=0.008$. Children consumed fewer French Fries and chips at the post-test compared to their responses at the pretest assessment. There were no significant differences for the other items at the two time points; however, mean differences were in directions indicating healthier eating at post-test. Six of the children in the younger group completed a question assessing their perceptions of whether participating in the Healthy Eating classes improved their knowledge about healthy eating. Three of the children reported that their knowledge improved, 1 reported improved "a lot", and two endorsed "amazing improvement".

\section{Qualitative Analyses}

Four coders met three times and reviewed younger children's drawings of their refrigerators and healthy lunches as well as older children's commercials and games as well as any notes or observations recorded by group leaders. Coders reviewed the information and determined common categories in the data. The first two meetings were used to review information and coders developed ideas for themes or categories in the children's products. During the third meeting the coders reviewed the data again and determined, via consensus, the common ideas in the children's work products. These ideas are described in the following sections for the younger and older group.

Younger Group: My Refrigerator and Healthy Lunch Drawings. There were wide individual differences in the amounts and types of food in each children's refrigerator. There typically was ranch dressing, catchup, and mustard in each refrigerator. Fruits usually were apples and oranges. The most common vegetable was carrots. Meats typically were hotdogs or bologna. Pizza and milk also were staples in most refrigerators. The coders reviewed children's drawings of what they packed in their lunches. Most drawings depicted at least 2 "junk or snack foods" such as chips or gummy worms. Vegetables typically were not present; some children had a fruit. Many had leftovers, such as a meat dish. After a few groups children were again asked to draw their ideas of a healthy lunch. The second round of drawings was reviewed and children added fruits and vegetables, and field notes made by researchers indicated that the children reported that they would pack more of these items in their lunches. Analysis of notes from groups and notes recorded while children were drawing indicated that children either did not mention or did not always understand the meaning of foods in the yellow food group. Most of their discussions focused on red and green food categories, for which they showed a good understanding.

Older Group: Games and Commercials. Games focused on reduction of red foods and increasing one's knowledge of green or healthy foods so that one could eat more of them. Several of the games were designed as question and answer to name healthy (green) and unhealthy food (red). These games were similar to Jeopardy and other quiz show games, with colorful props for children to use. In general games stressed the importance of increasing intake of green foods and reducing the intake of red foods and the message that this would lead to a "healthier" lifestyle. Yellow foods were either not mentioned or infrequently mentioned, without much explanation demonstrating comprehension of this food category.

When developing commercials several of the adolescents in the small groups developed jingles or songs, often to rap music. Here is one jingle or song,

"I know you like soda and lots of chips, but you need to eat something like asparagus. Eggrolls are good and salami too, you need to eat healthy, eat some honeydew."

Here is another jingle or song,

"Broccoli and carrots are all green food. Donuts and muffins are not really cool. Olives, meatloaf, omelet and nectarines are foods that are in-between. Chili and granola can raise blood pressure, chose the healthy foods it's the best gesture."

In games and commercials, green foods were typically referred to as "healthy" foods and red "foods" were referred to being unhealthy. Again, little reference was made to "yellow foods". Coders reported that adolescents' understanding of yellow foods lagged behind their knowledge about and understanding of when and how many red and green foods they should eat. The foods that 
were most commonly mentioned were fruits, as a green food, and red foods. Adolescents discussed how red foods tasted good, but weren't all that "good for you". The older youth loved fruits and were open to discussion of eating more fruits. Exercise was not typically mentioned in the commercials and games developed by the older youth. It was evident that references to changing activity levels were lacking in the games or commercials developed by the older children.

\section{DISCUSSION}

Results of this study indicated that knowledge about the Traffic Light Diet improved and children were satisfied with the program [9]. These findings were consistent with other programs showing success in adapting the Traffic Light Diet for schools, such as the Winning with Wellness Program [8]. Children also reported change in eating behaviors, indicating that they had absorbed information about this program in a relatively small number of group meetings. Findings from quantitative analyses showed that adolescents in the older group reported consuming more vegetables at the end of their classes. Children in the younger group stated that they were consuming fewer French fries and chips at the end of their groups. Inspection of the means for the healthy eating questions did indicate change in the direction of "healthier" eating, but results were not statistically significant for the majority of questions, which could have occurred because the sample size for this study was small.

Analysis of younger children's drawings and comments they provided about their artwork and analysis of games and commercials developed by older children indicated that they had successfully learned information about the Traffic Light Diet [9] as a result of their participation in the Children's Healthy Eating and Exercise Program. Results also indicated that children tended to focus on the green and red food categories, displaying less knowledge about the yellow food category. Coders believed that the yellow foods were more difficult to categorize and understand as foods to "watch" in terms of being careful not to consume too much of them. It may be that with more sessions, and greater explanation, children and adolescents could have demonstrated a better understanding of yellow foods.

A significant proportion of the children did not complete the post-intervention questionnaire. This occurred because they missed the final group or did not provide assent to complete the questionnaire. All of the children participated in art and other creative activities, such as developing commercials and games. Activities capitalizing on creativity and oral report of learning were favored. Capitalizing on the strong oral tradition in the Appalachian culture may be a preferred method for gathering evaluative data when implementing prevention programs
[14]. Additionally, exercise change was rarely mentioned in interviews or discussion groups by children. Learning about ways to help children learn the importance of exercise and increasing daily activity levels is a goal for future prevention programming. Furthermore, finding methods to assess whether children's knowledge was relayed to parents and resulted in actual change in their lives needs to be assessed in future studies. There are several other factors that may have limited the generalizability of study findings, including the small sample size utilized for this pilot project, using only child report to assess outcomes, and the differences in sessions between the older and younger children's groups. However, the project was successfully delivered in an urban area with very low-income families and successful results, especially when utilizing qualitative methods to gather data, were recorded.

When delivering this program several lessons were learned and these may be of benefit to others developing prevention programs for youth in urban settings. First, children gravitated toward creative activities, interviews and discussions. Also, there were wide individual differences in the amounts of exercise each child engaged in. It may be that rather than discussing activity levels in groups, one-on-one time with a group leader would have motivated the children to engage in more activities. Daily activity is a cornerstone of maintaining a healthy weight and lifestyle $[2,11,12]$, and finding ways to incorporate this message into future prevention programming is important. Anecdotal data revealed that children in the younger group really enjoyed discussing the red and green foods they ate in meals provided at the end of the group. Incorporating eating and discussion of the Traffic Light Diet into prevention programming may be an optimal teaching tool in prevention groups.

\section{CONCLUSION}

Our results add information about what components of information and prevention techniques work when teaching children about the Traffic Light Diet in a relatively small number of meetings in community programs. Specifically, when there are relatively few sessions to train children, it may be important to focus on discussing eating fewer red and a greater number of green foods. Another idea is to reinforce the "yellow" food category each session, in order to determine if this helps children or adolescents retain this information. Parents' involvement was not a cornerstone of this pilot program. Involving parents and other family members in the program may be a key to impact all realms of a child's eating and exercise habits. Further information on individual impact of the Children's Healthy Eating and Exercise Program could be obtained by using a case study design, 
where detailed information is gathered on child progress and change in activity level and weight also could be measured. In future studies, more rigorous examination of the effectiveness of dissemination studies assessing the impact of the Traffic Light Diet in urban settings will provide further information on the community impact of this program for instruction related to obesity prevention in children.

\section{REFERENCES}

[1] Ogden, C.L., Carroll, M.D., Curtin, L.R., McDowell, M.A., Tabak, C.J. and Flegal, K.M. (2006) Prevalence of overweight and obesity in the United States, 1999-2004. Journal of the American Medical Association, 295, 15491555. http://dx.doi.org/10.1001/jama.295.13.1549

[2] Davis, M.M., Gance-Cleveland, B., Hassink, S., Johnson, R., Paradis, G. and Resnicow, K. (2007) Recommendations for prevention of childhood obesity. Pediatrics, $\mathbf{1 2 0}$, S229-S253. http://dx.doi.org/10.1542/peds.2007-2329E

[3] Riggs, N.R., Sakuma, K. and Pentz, M.A. (2007) Preventing risk for obesity by promoting self-regulation and decision-making skills: Pilot results from the PATHWAYS to Health Program (PATHWAYS). Evaluation Review, 31, 287-310. http://dx.doi.org/10.1177/0193841X06297243

[4] Reynolds, K.D. and Spruijt-Metz, D. (2006) Translational research in childhood obesity prevention. Evaluation and the Health Professions, 29, 219-245. http://dx.doi.org/10.1177/0163278706287346

[5] Bauer, K.W., Yang, Y.W. and Austin, S.B. (2004) How can we stay healthy when you're throwing all of this in front of us? Findings from focus groups and interviews in middle schools on environmental influences on nutrition and physical activity. Health Education and Behavior, 31, 34-46. http://dx.doi.org/10.1177/1090198103255372

[6] Vanhala, M., Korpelainen, R., Tapanainen, P., Kaikkonen, K., Kaikkonen, H., Saukkonen, T. and Keinänen-Kiukaanniemi, S. (2009) Lifestyle risk factors for obesity in 7-year-old children. Obesity Research \& Clinical Practice, 3, 99-107.

http://dx.doi.org/10.1016/j.orcp.2009.01.003

[7] Roblin, L. (2007) Childhood obesity: Food, nutrient, and eating-habit trends and influences. Applied Physiology, Nutrition, \& Metabolism, 32, 635-645.

http://dx.doi.org/10.1139/H07-046

[8] Schetzina, K.E., Dalton, W.T., Lowe, E.F., Azzazy, N., VonWerssowetz, K.M., Givens, C., Pfortmiller, D.T. and Stern, H.P. (2009) A coordinated school health approach to obesity prevention among Appalachian youth: The winning with wellness pilot project. Family \& Community Health, 32, 271-285.

http://dx.doi.org/10.1097/FCH.0b013e3181ab3c57

[9] Epstein, L.H. (2005) The traffic light childhood weight control program: Traffic light: Kids program. University of Buffalo, Amherst.

[10] Epstein, L.H., Gordy, C.C., Raynor, H.A., Beddome, M., Kilanowski, K. and Paluch, R. (2012) Increasing fruit and vegetable intake and decreasing fat and sugar intake in families at risk for childhood obesity. Obesity, 9, 171178. http://dx.doi.org/10.1038/oby.2001.18

[11] Sothern, M.S. (2004) Obesity prevention in children: Physical activity and nutrition. Nutrition, 20, 704-708. http://dx.doi.org/10.1016/j.nut.2004.04.007

[12] Stice, E., Shaw, H. and Marti, C.N. (2006) A meta-analytic review of obesity prevention programs for children and adolescents: The skinny on interventions that work. Psychological Bulletin, 132, 667-691. http://dx.doi.org/10.1037/0033-2909.132.5.667

[13] Erickson, S.J., Gerstle, M. and Feldstein, S.W. (2005) Brief interventions and motivational interviewing with children, adolescents, and their parents in pediatric health care settings. Archives of Pediatric and Adolescent Medicine, 159, 1173-1180.

http://dx.doi.org/10.1001/archpedi.159.12.1173

[14] Schoenberg, N.E., Hatcher, J. and Dignan, M.B. (2008) Appalachian women's perceptions of their community's health threats. Journal of Rural Health, 24, 75-83. http://dx.doi.org/10.1111/j.1748-0361.2008.00140.x 